\section{Marília Greco'}

Ana P. Silva'

Edgar Merchán-Hamann"

Mauro L. Jeronymo'

Julio C. Andrade'

Dirceu B. Greco"'I

Centro de Vacinas anti-HIV. Universidade Federal de Minas Gerais (UFMG). Belo Horizonte, MG, Brasil

" Departamento de Saúde Coletiva. Faculdade de Ciências da Saúde. Universidade de Brasília. Brasília, DF, Brasil

III Departamento de Clínica Médica. Faculdade de Medicina. UFMG. Belo Horizonte, MG, Brasil

\author{
Correspondence: \\ Marília Greco \\ Avenida Prof. Alfredo Balena, 190 \\ $3^{\circ}$ andar / DIP \\ 30130-100 Belo Horizonte, MG, Brazil \\ E-mail: mgreco@medicina.ufmg.br
}

\section{Differences in HIV-risk behavior of bisexual men in their relationships with men and women}

\begin{abstract}
OBJECTIVE: To describe bisexual men's behavior in terms of sexual identity, condom use, frequency of sexual intercourse and types of partners and to determine rates of inconsistent condom according to partner's gender.
\end{abstract}

METHODS: Cross-sectional study nested in a cohort of HIV-negative homosexual and bisexual men in the city of Belo Horizonte, Southeastern Brazil, followed up since 1994 (Horizonte Project). Of 1,025 subjects enrolled between 1994 and 2005, 195 volunteers who reported at admission having sexual relations with men and women during the previous six months were selected. A behavioral risk index, called Horizonte Risk Index, was estimated. It incorporates a constant assigned to each type of unprotected sexual act, adjusted for the number of sexual encounters.

RESULTS: Sexual activity with men predominated; most considered themselves as bisexual $(55 \%)$ and homosexual $(26 \%)$. During the six months prior to the study, median number of casual male partners (4) was higher than both casual female partners (2) and steady male or female partners (1). During vaginal sex with a steady partner, the rate of inconsistent condom use was 55\%, compared to $35 \%$ and $55 \%$ in anal insertive and anal receptive sex, respectively, with steady male partners. The index was higher for those having sex with men and women compared to those having sex either exclusively with women or men $(\mathrm{p}=0.004)$.

CONCLUSIONS: HIV risk behavior was more frequent among men who reported sexual activity both with men and women. Bisexual men display different sexual and protective behavior according to gender and steadiness of relationships, and female steady partners had more unprotected encounters.

KEY WORDS: HIV infections, transmission. Acquired immunodeficiency syndrome, prevention \& control. Bisexuality. Homosexuality, male. Contraception behavior. Sexual partners. Cross-sectional studies. Brazil.

\section{INTRODUCTION}

Most studies on men who have sex with men (MSM) include behaviorally bisexual men. However, little attention has been given to bisexual behavior, especially regarding perceived HIV risk. In Brazil, approximately $10 \%$ of AIDS cases reported to the Ministry of Health in the last five years fall into the bisexual exposure category.* Some studies indicate that individuals exhibiting bisexual behavior, together with injecting drug users, could constitute bridge populations

* Pereira CAM. O impacto da Aids, a afirmação da cultura gay e a emergência do debate em torno do masculino - fim da homossexualidade? In: Rios LF, Almeida V, Parker R, Pimenta C, Terto JV, organizadores. Homossexualidade: produção cultural, cidadania e saúde. Rio de Janeiro: Associação Brasileira Interdisciplinar de AIDS; 2004. p. 52-62. 
accounting for the increasing rate of HIV infection among women. ${ }^{6,8,17}$ However, recent studies indicate that male bisexual behavior may not correspond to its pervasive image as the culprit for HIV spread to female population. ${ }^{1,7, *}$ Nevertheless, there are few studies about men who have sex with men and women (MSMW). It is conceivable that information regarding bisexuals may be found sparsely distributed in data from studies that focus on homosexual men or on the broader MSM category.**

In regard to bisexuals, there are factors related to HIV risk perception and practices for the prevention of HIV infection that have yet to be elucidated. It is possible that factors related to differing risk perceptions regarding their sexual relations with men and women, as well as self-reported sexual orientation, can influence effective condom use. Better understanding of these factors could facilitate the formulation of specific prevention strategies for this category, which constitutes a hardto-reach population group.

The objective of the present study was to describe individuals reporting bisexual behavior in an open cohort of MSM regarding condom use, steady and casual partnerships, number of partners and self-reported sexual identity. An attempt on establishing/finding potential differences in the practice of safer sex with men and women was made.

\section{METHODS}

This was a cross-sectional study nested in an ongoing cohort of homosexual and bisexual men (Horizonte Project) conducted in Belo Horizonte, Southeastern Brazil. The cohort was established in 1994. The study protocol of the cohort consists of two phases: screening (recruitment and inclusion) and follow-up. All volunteers are evaluated every semester by a multidisciplinary team that includes professionals from psychosocial, clinical, epidemiological, and laboratory research areas.

The objective of recruitment is to identify HIV-negative MSM over the age of 18. Recruitment has mainly been achieved by word of mouth. Other means are the use of flyers, pamphlets, and notices in community newspapers, and radio and television advertisements.

The objectives of the follow-up phase are: a) to determine incidence of HIV infection; $b$ ) to evaluate the impact of educational interventions and counseling on the incidence of HIV infection; c) to identify volun- teers who would participate in future clinical trials of HIV/AIDS vaccine. A detailed description of design and methodology of Project Horizonte was previously published. ${ }^{3,4}$

From Project Horizonte database, there were selected all subjects who, at admission, between 1994 and 2004, reported having ever had sex with men and women. Time of admission was chosen in order to provide a broader view of bisexual subjects prior to exposure to the project interventions. Out of 1,025 volunteers enrolled between 1994 and 2005, 195 (19.0\%) reported, in the initial questionnaire, having had sex with men and women. These 195 volunteers constituted the study population.

All subjects were interviewed individually by the psychosocial team by means of a semi-structured questionnaire comprising 96 questions. Closed questions concern sociodemographic variables, sexual practices, risk perception, condom use and drug use. Open questions investigated self-reported sexual identity, social perception of their own sexual orientation, and discrimination.

The following variables were included in the analysis: demographic variables such as age, marital status, educational level, self-reported race, income; variables regarding sexual practices in the previous six months such as type of partner (male and/or female); type of partnership (steady or casual); type of sexual act (anal insertive, anal receptive or vaginal); number of partners; condom use; and self-reported sexual identity.

Self-reported sexual identity was determined by the open question: "What word do you use to define your sexuality and why?" The classification system previously established for this cohort was applied.***

Partnerships were defined as steady when subjects reported emotional involvement and continuity of encounters (not necessarily based on relationship duration); and casual when subjects reported lack of emotional attachment and/or uncertainty about a new encounter; the latter includes anonymous partners.

Subjects indicated the number and type of partnerships (steady or casual; with men or women) in the six months prior to the interview. For the purpose of the present study, sexual practices with men included anal insertive or receptive sex while sexual practices with women included vaginal or anal sex. Condom use was classified as consistent (condoms always used) or inconsistent (condoms used occasionally or never).

\footnotetext{
* Lago RF. Bissexualidade masculina: dilemas de construção de identidade sexual [master's dissertation]. Rio de Janeiro: Instituto de Medicina Social da UERJ; 1999.

** Seffner F. Derivas da masculinidade: representação, identidade e diferença no âmbito da masculinidade bissexual [doctorate thesis]. Porto Alegre: Faculdade de Educação da UFRGS; 2003.

*** Ministério da Saúde. Coordenação Nacional de DST e Aids. Bela Vista e Horizonte: Estudos comportamentais e epidemiológicos entre homens que fazem sexo com homens. Brasília; 2000. (Série Avaliação, 5).
} 
Subsequently, steady and casual partnerships were analyzed separately, considering that individuals might report both steady and casual partnerships, and also various sexual practices with sexual partners of either or both genders, and with varying consistency of condom use.

To achieve a global and comprehensive estimate of sexual risk behaviors, it was referred to an index used in a survey of Brazilian army conscripts (index of sexual risk behavior - ICSR) carried out by Szwarcwald et al. ${ }^{15}$ As ICSR was used to evaluate sexual behavior of younger and predominantly heterosexual subjects, it would unlikely be suitable to the present study population. Thus, it was created an index partially based on ICSR but considering the more detailed questionnaire of Project Horizonte and the need for a scale tailored to specific characteristics of the population studied. This index was called Horizonte Risk Index (IRH) and it added up the contributing risk components of each type of unprotected sexual act. Each component is the product of a constant, related to its epidemiological relevance and number of sex acts where such type of unprotected sexual practice occurred. The following constant values were used for each risk component:

- unprotected anal receptive sex with a casual or steady partner: 0.5 ;

- unprotected anal insertive sex with a casual or steady male partner: 0.4 ;

- unprotected anal sex with a casual or steady female partner: 0.3 ;

- unprotected vaginal sex with a casual or steady partner: 0.2 .

The reported number of sexual encounters was converted into a logarithm due to the distortion caused by extreme values. Subjects who reported a given sexual behavior without specifying how many times were excluded. Then, IRH formula was:

$$
\operatorname{IRH}=\sum_{\mathrm{i}=1}^{\mathrm{n}}\left(\mathrm{C}_{\mathrm{i}} \times \mathrm{P}_{\mathrm{i}}\right) \log (\mathrm{N})
$$

$\mathrm{n}$ : each type of a given sexual practice and partnerships

P: indicates if the practice was performed or not

$\mathrm{C}$ : constant value attached to each sexual practice

$\mathrm{N}$ : number of episodes for each sexual practice

The prevalence of reported sexual practice was measured as frequency. IRH in the various categories were compared by their medians, and dispersion estimates, by the quartiles. Non-parametric Kruskal-Wallis and median tests were used for assessing differences found in median number of partners and scale values. A level of $\mathrm{p}<0.05$ was considered statistically significant. EpiInfo 6.04d and SPSS 13.0 programs were used for analyses and recodifications.

Horizonte Project was approved by the University Hospital Research Ethics Committee of the Universidade Federal de Minas Gerais, and has been carried out in compliance with national and international ethical requirements. All volunteers signed a written informed consent form.

\section{RESULTS}

Study subjects were between 18 and 70 years of age $($ mean $=27.8$ years; median=26). Table 1 shows main sociodemographic variables. Most were single and reported being currently employed. Also, they were homogeneously distributed among educational level

Table 1. Sociodemographic characteristics of bisexual subjects. Belo Horizonte, Southeastern Brazil, 1994-2005.

\begin{tabular}{|c|c|c|}
\hline Variable & $\mathrm{N}$ & $\%$ \\
\hline \multicolumn{3}{|l|}{ Marital status } \\
\hline Single & 171 & 87.7 \\
\hline Married & 12 & 6.2 \\
\hline Divorced & 10 & 5.1 \\
\hline Other & 2 & 1.0 \\
\hline \multicolumn{3}{|l|}{ Schooling* } \\
\hline Elementary and middle school & 55 & 28.5 \\
\hline High school & 76 & 39.4 \\
\hline University & 62 & 32.1 \\
\hline \multicolumn{3}{|l|}{ Currently employed } \\
\hline Yes & 148 & 75.9 \\
\hline No & 47 & 24.1 \\
\hline \multicolumn{3}{|l|}{ Income* $\left(\mathrm{MW}^{* *}\right)$} \\
\hline No income & 26 & 13.5 \\
\hline Less than 1 & 2 & 1.0 \\
\hline $1-3$ & 74 & 38.3 \\
\hline $4-6$ & 41 & 21.2 \\
\hline $7-10$ & 18 & 9.3 \\
\hline $11-14$ & 13 & 6.7 \\
\hline 15 or more & 19 & 9.8 \\
\hline \multicolumn{3}{|l|}{ Self-reported race* } \\
\hline White & 75 & 38.5 \\
\hline Black & 20 & 10.3 \\
\hline Pardo & 98 & 50.3 \\
\hline
\end{tabular}

*Numbers do not add up to 195 individuals due to missing values.

** MW: Brazilian minimum monthly wage. $(1 \mathrm{MW}=\mathrm{R} \$$ 300 - approximately US\$80). 
Table 2. Sexual behavior, preference and self-reported sexual identity among bisexual subjects. Belo Horizonte, Southeastern Brazil, 1994-2005.

\begin{tabular}{lrr}
\hline Variable & N & $\%$ \\
\hline Current sexual behavior & 24 & 12.3 \\
Have sex with men and women equally & 141 & 72.3 \\
Have sex mainly with men and occasionally with women & 30 & 15.4 \\
Have sex mainly with women and occasionally with men & 35 & 17.9 \\
Sexual preference* & 3 & 1.5 \\
Sexually aroused by men and women equally & 111 & 56.9 \\
Sexually aroused by women only & 21 & 10.8 \\
Sexually aroused mainly by men and occasionally by women & 24 & 12.3 \\
Sexually aroused mainly by women and occasionally by men & 108 & 55.4 \\
Sexually aroused by men only & 51 & 26.2 \\
Self-reported sexual identity & 15 & 7.7 \\
Bisexual & 7 & 3.6 \\
Homosexual & 14 & 7.2 \\
Entendido** & & 5 \\
Gay & & \\
Other & & \\
\hline
\end{tabular}

* Numbers do not add up to 195 individuals due to missing values.

** Non-derogatory informal Brazilian Portuguese term for homosexual

categories. About 52.2\% earned less than three minimum monthly wages (around US\$ 80 ) or had no income. As for race, half $(50.3 \%)$ reported being "pardo," of mixed racial descent.

The majority (72.3\%) of respondents reported engaging in sexual activity mainly with men and occasionally with women (Table 2). Approximately 56.9\% were

Table 3. Condom use among bisexual subjects in sexual encounters* with men and women according to type of partnership and sexual practice. Belo Horizonte, Southeastern Brazil, 1994-2005.

\begin{tabular}{lcc}
\hline $\begin{array}{l}\text { Type of partnership/ } \\
\text { Sexual practice }\end{array}$ & \multicolumn{2}{c}{ Consistent } \\
& $\mathrm{N}$ & $\%$ \\
\hline $\begin{array}{l}\text { Steady male partner }(\mathrm{N}=109) \\
\quad \text { Anal insertive }\end{array}$ & 71 & 65.1 \\
$\quad$ Anal receptive & 48 & 44.0 \\
$\quad$ Casual male partner $(\mathrm{N}=156)$ & & \\
$\quad$ Anal insertive & 106 & 67.9 \\
$\quad$ Anal receptive & 63 & 40.4 \\
Steady female partner $(\mathrm{N}=56)$ & & \\
$\quad$ Vaginal & 25 & 44.6 \\
$\quad$ Anal & 11 & 19.6 \\
Casual female partner $(\mathrm{N}=70)$ & & \\
$\quad$ Vaginal & 51 & 72.9 \\
$\quad$ Anal & 23 & 32.9 \\
\hline
\end{tabular}

*Partnerships and sexual practices in the previous six months. sexually aroused mainly by men and occasionally by women. Slightly more than half described themselves as bisexual, and approximately one-quarter described themselves as homosexual. "Entendido," a Brazilian Portuguese informal term for homosexual and gay was less frequently used. Other terms, most of them derogatory such as bicha, viado, boiola, baitola were used by $7 \%$ of the subjects.

Self-reported sexual identity was compared to current sexual behavior (data not shown). Of 108 subjects selfidentified as bisexual, 57.4\% reported that they had sex mainly with men and occasionally with women, $25.9 \%$ mainly with women and occasionally with men, and $16.7 \%$ equally with both men and women. Of 51 subjects who reported themselves as homosexual, 94.1\% said that they had sex mainly with men and occasionally with women.

Out of 195 subjects, 109 (55.9\%) had between one and eight steady male partners in the previous six months (mean=1.23; median=1). As to casual partners of the same sex, $152(77.9 \%)$ had between 1 and 100 $($ mean $=8.39$; median=4). Fifty-six subjects $(28.7 \%)$ had steady relationships with women in the previous six months, ranging from one to five (mean=1.27; median=1). Sixty-nine (35.4\%) had at least one casual female partner in the same period, ranging from 1 to 30 $($ mean $=3.9$; median $=2$ ). The difference between these medians was significant $(\mathrm{p}<0.0001)$.

Among those who had sexual intercourse with steady partners in the previous six months, the median number 
Table 4. Risk scale values according to type of partnership with men and women among bisexual subjects*. Belo Horizonte, Southeastern Brazil, 1994-2005.

\begin{tabular}{llccc}
\hline $\begin{array}{l}\text { Type of partnership } \\
\text { (in the last 6 month) }\end{array}$ & Statistics & Sex with men only & $\begin{array}{c}\text { Risk scale (IRH)** } \\
\text { Sex with women only }\end{array}$ & $\begin{array}{c}\text { Sex with both men } \\
\text { and women }\end{array}$ \\
\hline Steady partner & $\mathrm{N}$ & 16 & 1 & 2 \\
& Range & $0.047 ; 3.340$ & 0.170 & $0.630 ; 1.500$ \\
& Mean & 1.00 & 0.170 & 1.070 \\
& Interquartile range & $0.300 ; 0.740$ & 0.170 & $0.630 ; 1.500$ \\
Casual partner & Median & 0.740 & 0.170 & 1.070 \\
& N & 8 & 0 & 25 \\
& Range & $0.038 ; 1.269$ & 0 & $0.019 ; 2.280$ \\
& Mean & 0.430 & 0 & 0.810 \\
& Interquartile range & $0.040 ; 0.228$ & 0 & $0.148 ; 0.705$ \\
& Median & 0.220 & 0 & 0.700 \\
& $\mathrm{~N}$ & 22 & 2 & 41 \\
& Range & $0.047 ; 3.190$ & $0.220 ; 0.930$ & $0.070 ; 4.670$ \\
& Mean & 0.869 & 0.570 & 1.100 \\
& Interquartile range & $0.244 ; 0.565$ & $0.226 ; 0.931$ & $0.574 ; 1.641$ \\
& Median & 0.565 & 0.570 & 0.820 \\
\hline
\end{tabular}

* Includes 117 subjects who were at risk in the six months previous to the interview.

** IRH: Horizonte Risk Index

of partners was significantly higher for those who had sexual relations with men and women than for those who had intercourse exclusively either with men or women ( $p=0.004)$. Similarly, among those who reported casual partners, the median number of partners was also significantly higher for those who had sexual relations with both men and women $(\mathrm{p}=0.009)$.

Table 3 shows condom use, type of partnership and sexual practices of 195 subjects with male and female partners. In regard to sexual relations with women, the rate of consistent condom use with steady partners was notably lower than that with casual partners regardless of the type of sexual act. Although they engaged less in sexual practices, it is noteworthy that the lowest rate of consistent condom use was reported for anal sex with both steady and casual female partners (19.6\% and $32.9 \%$, respectively). Consistent condom use in vaginal intercourse with steady partner was reported by less than half of the respondents in the previous six months. This rate was similar to that of consistent protection in anal receptive sex with steady male partner (about 44\%).

IRH scores showed a mean of 0.92 ; median of 0.77 ; mode of 0.047 ; interquartile range between 0.28 and 1.26 ranging from 0.019 to 4.675 . Its distribution was skewed toward the left due to the small number of subjects with high scores.

Table 4 shows IRH distribution by type of partnership (steady only, casual only or both) and gender of sexual partners (only male, only female or both) in the previous six months. For those categories with a relevant number of respondents, the highest scores were seen in those who had sex both with steady and casual partners who were men and women (median=0.82). Among 25 subjects who reported sex with casual partners, men and women, the median score was 0.70 , whereas among those 22 reporting steady and casual partnerships with men only it was 0.56 . Sixteen subjects who had sex with steady partners who were men had a median IRH of 0.74 , whereas eight volunteers reporting sex with casual male partners had 0.22 .

There were statistically significant differences in medians over the previous six months when those who reported having sex exclusively with women were compared to those reporting having sex exclusively with men and to those having sex with both men and women (Figure). The latter group had the highest IRH scores $(p=0.004)$. When types of partnerships - exclusively casual, exclusively steady and both casual and steady - were compared, the category in which subjects had both steady and casual partnerships showed the highest risk level but there was not a statistically significant difference among median IRH scores of the three groups $(p=0.22)$. There were median IRH differences among married, single, separated and other marital status, the latter presenting the highest scores $(\mathrm{p}=0.015$; data not shown). IRH was not associated with age $(\mathrm{p}=0.28)$, selfreported sexual identity $(0.77)$, current sexual behavior or sexual preference $(\mathrm{p}=0.43)$. 

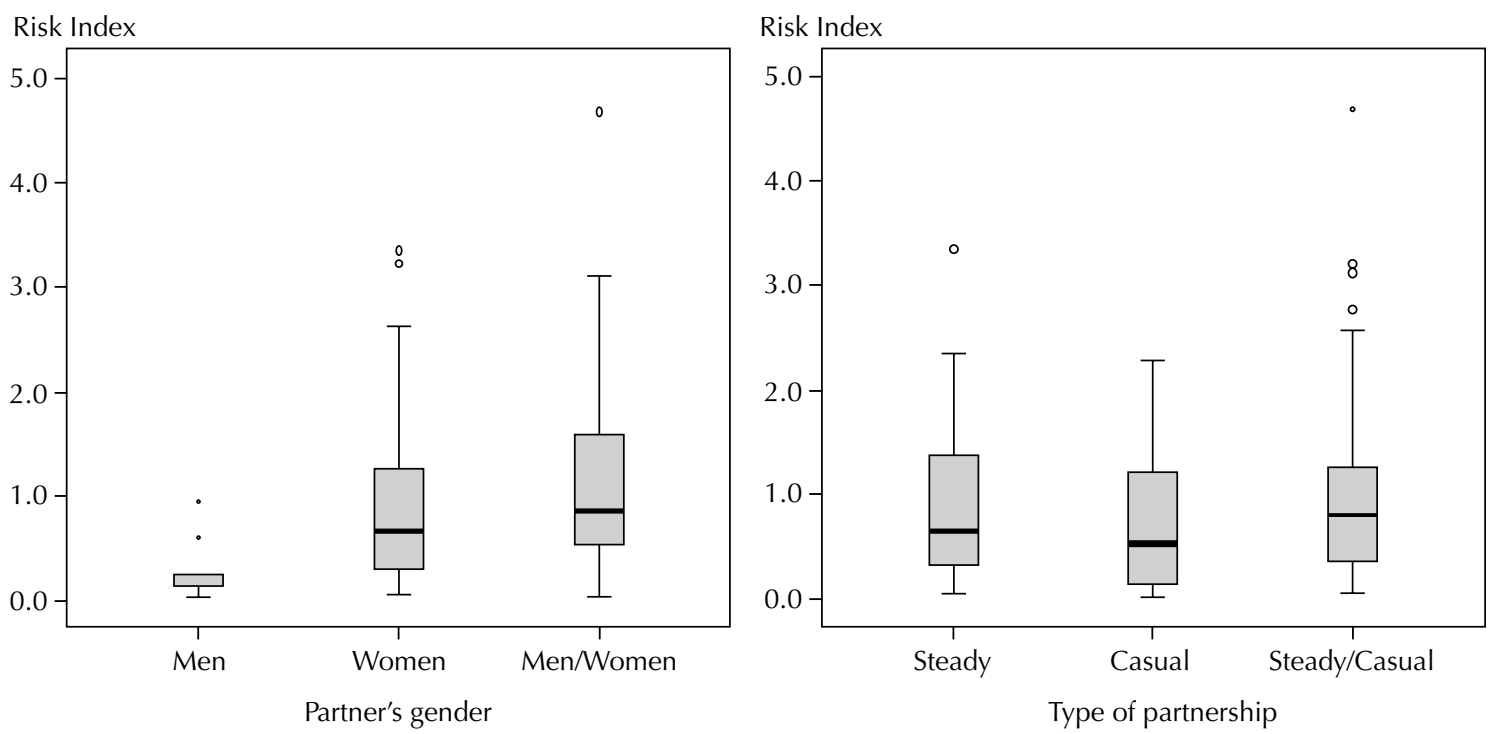

Figure. Sexual risk scale (IRH) scores among bisexual subjects, comparing partnerships with men to partnerships with women and steady partnerships to casual partnerships. Horizonte Project, 1994-2005.

\section{DISCUSSION}

In the present study of a subset of Horizonte Project subjects reporting bisexual behavior were more sexually aroused by, and had sex predominantly with men, and also had a higher number of male partners. Safe sex was more frequent with casual than with steady partners and unprotected sexual intercourse with women was noteworthy. The risk level estimated by IRH score was higher for those with sexual activity with both men and women in the last six months.

There are few data from cohort studies of Brazilian MSM and MSMW that are comparable to those here presented. Similar cohort studies of MSM have been conducted in two other Brazilian cities (São Paulo and Rio de Janeiro). ${ }^{14, *}$ A finding highlighted in these studies is the asymmetric frequency of unprotected sex between steady and casual partners. In the São Paulo study, consistency of safe sex practices in anal intercourse with steady partners $(66 \%)$ was lower than in anal intercourse with casual partners (86\%).* The Rio de Janeiro study also showed that safe sex practices in anal insertive and anal receptive intercourse were less frequent with steady partners (mean 63\%) than with casual partners (mean, $68 \%$ ). ${ }^{14}$ In the present study these rates of protected behavior were lower. However, in São Paulo and Rio de Janeiro studies, ${ }^{14, *}$ as in similar cohort studies conducted in other countries, ${ }^{16}$ bisexuals were not evaluated separately. In those studies, intercourse with women was not taken into account, and the types of partnership were included without specifying which individuals engaged in any given behavior.

The results of the present study show safe sex was less common in sexual practices with women. In a study carried out in California, US, it was found a lower rate of condom use among bisexual than homosexual men, and safe sex practices were also less common in intercourse with women. ${ }^{12}$ Also, safe sex practices were more common in anal sex between men. In a study carried out at the $8^{\text {th }}$ Gay-Lesbian-Bisexual-Transgender-Pride Parade in Rio de Janeiro, two-thirds of self-reported bisexual MSM used condoms consistently compared to $82 \%$ of homosexual MSM and $92 \%$ of transgender individuals. ${ }^{5}$

Other authors have concluded that bisexual men are different from other segments of homosexually active population, including certain risk behaviors. Agronick et $\mathrm{al}^{1}$ found that young self-reported bisexual men of Latin-American descent, interviewed at venues attended by New York gay community members, reported having a larger number of partners and unprotected sex more often. In a survey of individuals regulars of gay entertainment venues in Saint Petersburg, Russia, the number of male partners was higher for bisexuals than for exclusively homosexuals. ${ }^{9}$ A study based on a probabilistic sample of Mexico City residents ${ }^{7}$ also showed a higher number of male than female partners among bisexuals. According to a population-based study of young North American men, those who hid their sexual orientation (nondisclosers), not necessarily bisexuals, also sought counseling and testing less frequently. ${ }^{13}$

\footnotetext{
* Ministério da Saúde. Coordenação Nacional de DST e Aids. Bela Vista e Horizonte: Estudos comportamentais e epidemiológicos entre homens que fazem sexo com homens. Brasília; 2000. ( Série Avaliação, 5)

** Seffner F. Derivas da masculinidade: representação, identidade e diferença no âmbito da masculinidade bissexual [tese de doutorado]. Porto Alegre: Faculdade de Educação da Universidade Federal do Rio Grande do Sul; 2003.
} 
In cohort studies of MSM, due to the all-encompassing behavioral category used, the discussion of bisexuality converges with that of homosexuality.* Some studies use self-reporting to divide into two population segments. In the present study, as in others, ${ }^{9,13}$ a behavioral definition was used based on the account of previous sexual experiences with men and women. This methodological choice seems to be appropriate as the behavioral realm has an interface with HIV infection probabilities. Besides using sexual behavior as a defining criterion, the present study also considered self-reported sexual identity to characterize the study population. Although bisexual volunteers of Horizonte Project reported sexual activity with men and women, $51 \%$ had sexual relations exclusively with men in the previous six months. In the aforementioned Russian study, ${ }^{9} 80 \%$ of subjects reported having had both male and female partners at some time in their lives. However, within the last three months, women comprised only $37 \%$ of sexual encounters. The same authors noted a higher proportion of bisexuals in meeting places for homosexual encounters than in entertainment spots associated with urban gay culture. Bisexuals also had commercial sex more often than those described as gay. These findings reinforce the idea that the proportion of bisexuals is determined by the population recruited for the studies.

With respect to self-reported sexual identity, in the present study only slightly more than half of the men with a previous history of sexual intercourse with men and women described themselves as bisexuals. In a similar cohort followed up in Rio de Janeiro (Praça Onze Project), 57\% of 102 self-reported bisexual men had sex with men and women within the preceding six months, whereas $43 \%$ had sex exclusively with men.** In a study of subscribers to a magazine targeted to the gay public in Spain, ${ }^{2}$ only $4.5 \%$ described themselves as bisexuals. In the study of the Gay Parade participants in Rio de Janeiro, ${ }^{5} 8.1 \%$ identified themselves as bisexuals. Since the present study is based on a cohort of MSM, bisexuals included in the analysis were likely to be more involved in the gay culture than others who probably would not volunteer for epidemiological studies.

Among the limitations of the present study, it is conceivable that volunteer subjects were more inclined to accept preventive interventions and therefore may not be representative of MSM as a whole. The cohort recruitment was achieved by word of mouth and was thereby limited to a certain sociocultural and sexual profile. With specific regard to behaviorally bisexual men, due to the stigma attached to homosexuality, the typical MSMW may not have been reached. In an attempt to avoid recall bias, risk practices were evaluated based on subject recollection in the previous six months. Nevertheless, this brief period might not accurately represent the real sexual experience. Another limitation of the study is that the scale values which emphasized the difference between types of partner and their coefficients were not adjusted to HIV prevalence in the population from where potential partners came from. Furthermore, the risk index used is intended to quantify the level of risk. Its importance should not be overemphasized since the scale was not submitted to a validation process and more studies are necessary to assess and validate its accuracy.

Results of some studies ${ }^{11, *}$ have indicated that higher vulnerability of bisexual men to HIV infection compared to homosexual men can be related to the social construction of masculinity. These authors have suggested that this category is the central organizer of the constructed representations of bisexuality. It is probable that at least part of the population designated as bisexual still use concealment strategies in order to avoid discrimination and isolation in their microsocial environment, as well as verbal and physical violence, thereby maintaining their reference to the social construct of hegemonic masculinity. In addition, Seffner* stated that anonymity and lack of social venues make it difficult to express bisexual identity. In a previous study of Horizonte Project, ${ }^{* * *}$ bisexual volunteers reported that they did not feel discriminated as they do not openly disclose their sexual identity. Other factors, such as difficulty in being accepted (since they circulate in two different milieux), prevailing cultural taboos against homosexuality, limited availability of information provided specifically to them, less access to professionals trained to deal with specific needs of bisexuality, are likely to make their situation more complex. ${ }^{10}$

The present study shows that consistent condom use was less common in steady partnerships with women. This contrasts with the emphasis on prevention measures focusing interactions among men that certainly do not target negotiation difficulties in relationships between these men and their female partners which are mediated by pervasive cultural silences of the heterosexual world. These difficulties underscore the need for more in-depth studies that could promote the implementation of prevention policies and programs. Since the present study reveals that MSMW and their partners

\footnotetext{
* Seffner F. Derivas da masculinidade: representação, identidade e diferença no âmbito da masculinidade bissexual [tese de doutorado]. Porto Alegre: Faculdade de Educação da UFRGS; 2003.

** Lago RF. Bissexualidade masculina: dilemas de construção de identidade sexual [dissertação de mestrado]. Rio de Janeiro: Instituto de Medicina Social da UERJ; 1999

*** Ministério da Saúde. Coordenação Nacional de DST e Aids. Bela Vista e Horizonte: Estudos comportamentais e epidemiológicos entre homens que fazem sexo com homens. Brasília; 2000. ( Série Avaliação, 5)
} 
take behavioral risks which clearly differ according to gender and stability of partnership, it becomes relevant to carefully examine the processes of identity construction by questioning and redefining standards of the hegemonic culture. Better understanding the identity construction and socialization processes of bisexuals would facilitate the adaptation of preventive practices to this hard-to-reach population.

\section{REFERENCES}

1. Agronick G, O'Donnell L, Stueve A, Doval AS, Duran R, Vargo S. Sexual behaviors and risks among bisexually- and gay-identified young latino men. AIDS Behav. 2004;8(2):185-97.

2. Cañellas S, Pérez de la Paz JP, Noguer I, Villaamil F, García-Berrocal ML, de la Fuente L, et al. Conductas sexuales de riesgo y prevalencia de infección por HIV en hombres con prácticas homo/bisexuales en la Comunidad de Madrid. Rev Esp Salud Publica. 2000;74(1):25-32.

3. Carneiro MCFA, Antunes CMF, Greco M, Oliveira El, Andrade JC, Lignani Jr L, et al. Design, implementation, and evaluation at entry of a prospective cohort study of homosexual and bisexual HIV-1-negative men in Belo Horizonte, Brazil: Project Horizonte. J Acquir Immune Defic Syndr. 2000;25(2):182-7.

4. Carneiro M, Cardoso FA, Greco M, Oliveira E, Andrade J, Greco DB, et al. Determinants of Human Immunodeficiency Vírus (HIV) prevalence in homosexual and bisexual men screened for admission to a cohort study of HIV negatives in Belo Horizonte, Brazil: Project Horizonte. Mem Inst Oswaldo Cruz. 2003;98(3):325-9.

5. Carrara S, Ramos S, Caetano M. Política, direitos e homossexualidade. 8a. Parada do Orgulho GLBT - Rio - 2003. Rio de Janeiro: Pallas; 2003.

6. Chu SY, Peterman TA, Doll LS, Buehler JW, Curran JW. Aids in bisexual men in the United States: epidemiology and transmission to women. Am J Public Health. 1992;82(2):220-4.

7. Isazola-Licea JA, Gortmaker SL, Gruttola V, Tolbert K, Mann J. Sexual behavior patterns and HIV in bisexual men compared to exclusively heterosexual and homosexual men. Salud Publica Mex. 2003;45(Supl 5): 662-71.

8. Kahn JG, Gurvey J, Pollack LM, Binson D, Catania JA. How many infections cross the bisexual bridge? An estimate from the United States. AIDS. 1997;11(8):1031-7.

9. Kelly JA, Amirkhanian YA, McAuliffe TL, Granskaya JV, Borodkina OI, Dyatlov RV, et al. HIV risk characteristics and prevention needs in a community

\section{ACKNOWLEDGEMENTS}

To Horizonte Project team and Prograna Nacional de DST/Aids of Brazilian Ministry of Health for their logistic support. To Dr. Carlos Cáceres (Universidad Cayetano Heredia, Lima, Peru), Dr. Norman Hearst (University of California, San Francisco, USA) for suggestions on the manuscript.

sample of bisexual men in St. Petersburg, Russia. AIDS Care. 2002;14(1):63-76.

10. Matteson DR. Bisexual husbands: integrating two worlds. In: Abbott F, editor. Men and intimacy: personal accounts exploring the dilemmas of modern male sexuality. Freedom, CA: Crossing Press; 1990. p. 134-42.

11. Pereira CAM. O impacto da Aids, a afirmação da cultura gay e a emergência do debate em torno do masculino - fim da homossexualidade? In: Rios LF, Almeida V, Parker R, Pimenta C, Terto JV, organizadores. Homossexualidade: produção cultural, cidadania e saúde. Rio de Janeiro: Associação Brasileira Interdisciplinar de AIDS; 2004. p.52-62.

12. Prabhu $\mathrm{R}$, Owen $\mathrm{CL}$, Folger $\mathrm{K}$, McFarland $\mathrm{W}$. The bisexual bridge revisited: sexual risk behavior among men who have sex with men and women, San Francisco, 1998-2003. AIDS. 2004;18(11):1604-6.

13. Shehan DA, LaLota M, Johnson DF, Celentano DD, Koblin BA, Torian LV, et al. HIV/STD risks in young men who have sex with men who do not disclose their sexual orientation - six US cities, 1994-2000. MMWR Morb Mortal Wkly Rep. 2003;52(5):81-6.

14. Souza CTV, Bastos FI, Lowndes CM, Szwarcwald CL, Santos EM, Castilho EA, et al. Perception of vulnerability to HIV infection in a cohort of homosexual / bisexual men in Rio de Janeiro, Brazil. Aids Care. 1999;11(5):567-79.

15. Szwarcwald CL, Castilho EA, Barbosa Jr A, Gomes MRO, Costa EAMM, Maletta BV, et al. Comportamento de risco dos conscritos do Exército Brasileiro, 1998: uma apreciação da infecção pelo HIV segundo diferenciais sócio-econômicos. Cad Saude Publica. 2000;16( Supl 1):113-28.

16. Valdiserri RO, Lyter D, Leviton LC, Callahan CM, Kingsley LA, Rinaldo CR. Variables influencing condom use in a cohort of gay and bisexual men. Am J Public Health. 1988;78(7):801-5.

17. Wood RW, Krueger LE, Pearlman TC, Goldbaum G. HIV transmission: women's risk from bisexual men. Am J Public Health. 1993;83(12):1757-9. 